\title{
Exhaust gas emissions evaluation in the flight of a multirole fighter equipped with a F100-PW-229 turbine engine
}

\author{
Jarosław Markowski ${ }^{1,}$, Maciej Kazimierczak ${ }^{1}$, Pawel Benedict $^{1}$, and Damian Olejniczak ${ }^{1}$ \\ ${ }^{1}$ Poznan University of Technology, Faculty of Machines and Transport, ul. Piotrowo 3, 60-965 Poznan, Poland
}

\begin{abstract}
The issue of exhaust gas emission generated by turbine engines described in ICAO Annex 16 of the International Civil Aviation Convention includes a number of procedures and requirements. Their implementation is aimed at determining the value of the engine's environmental parameters and comparing them to the values specified in the norms. The turbine engine exhaust gas emission test procedures are defined as stationary and the operating parameters values are set according to the LTO test. The engine load setting values refer to engine operating parameters that occur when the plane is in the vicinity of airports. Such a procedure is dedicated to civilian passenger and transport aircraft. The operating conditions of a multirole fighter aircraft vary considerably from passenger aircraft and the variability of their flight characteristics requires a special approach in assessing its environmental impact. This article attempts to evaluate the exhaust gas emissions generated by the turbine engine in a multirole fighter flight using the parameters recorded by the onboard flight recorder.
\end{abstract}

\section{Introduction}

Aircraft and passenger aircraft with turbine engines are normally operated in flight conditions at a selected altitude and at a selected speed, which translates into established operating parameters of the engines. There are several papers tackling the problems with addressing the exhaust emissions assessment issue for turbine engines in established flight conditions.

One of the characteristics of a multirole aircraft is the ability to perform various aviation tasks related to pursuit, air combat at various altitudes, interception and aerial reconnaissance or patrol $[1,2]$. All of these tasks differ from one another in terms of operating parameters: the altitude, speed or type of maneuvers performed (Fig. 1). These parameters are reflected in the operating characteristics of the drive unit, and thus of harmful exhaust components emissions from the engine [2-4].

All flight parameters listed above are reflected in propulsion system performance characteristics, and thus in emissions of toxic compounds contained in exhaust gas. State-of-the-art emission measurement technologies do not allow measuring toxic emissions in actual flight conditions. Collection of exhaust gas samples for analysis and safe installation of measurement equipment are the key challenges in this regard. Therefore, emissions of toxic compounds in exhaust gas are measured in a stationary LTO test. However, tests of this kind do not allow one to determine emission rates of each toxic compound in exhaust gas in actual operation conditions [2, 5-7]. Therefore, efforts are being made to develop new methods enabling a more accurate assessment of toxic emissions from multi-purpose aircraft. One of the concepts proposes to assess toxic emissions on the basis of functional connections between operation parameters and emission parameters. Therefore, it is of key importance to analyze operation parameters recorded by on-board flight recorders.

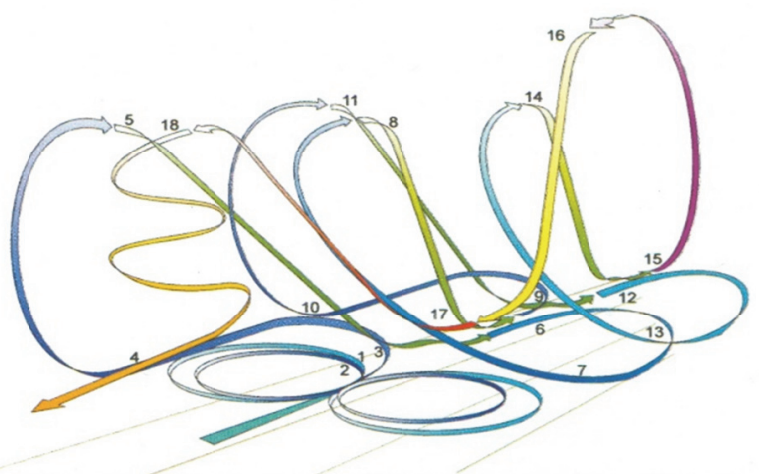

Fig. 1. Maneuvers of a multi-purpose aircraft while attacking ground targets [1]: 1 - turn by $45^{\circ}, 2$ - turn by $60^{\circ}, 3$ - half turn left, 4 - roll-off-the-top left, 5 - dive, 6 - half turn right, 7 - roll-off-the-top right, 8 - dive, 9 - half turn left, 10 - rolloff-the-top left, 11 - dive, 12 - half turn right, 13 - roll-off-thetop right, 14 - dive, 15 - Immelmann, 16 - dive, 17 - pull up, 18 - spiral.

Some of the many parameters recorded in this way may be helpful in analyzing operation conditions of the aircraft in general and its propulsion system in particular. For instance, to assess aircraft operation conditions one can use recorded changes in velocity $(v)$, flight altitude $\left(h_{f l y}\right)$, thrust lever positions $\left(P_{p}\right)$, exhaust gas temperature as well as afterburner on/off information, relative $1^{\text {st }}$ and

Corresponding author: jaroslaw.markowski@put.poznan.pl 
$2^{\text {nd }}$ stage turbine speeds $\left(n_{1}\right.$ and $\left.n_{2}\right)$, relative opening of the exhaust gas exhaust nozzle (WO), and instantaneous fuel consumption $\left(G_{e}\right)$ (Fig. 2).

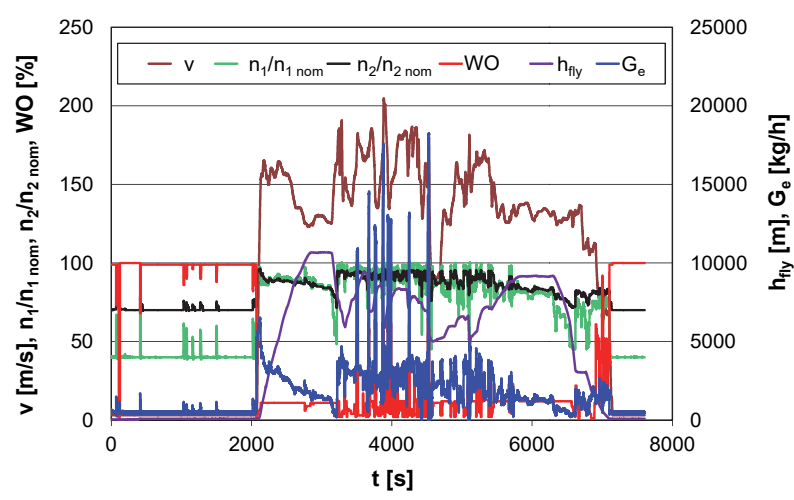

Fig. 2. Selected operation parameters of a multi-purpose aircraft and its engine recorded during the flight.

Once the operation conditions of an aircraft and its propulsion system have been measured, they can be linked to exhaust gas emission parameters [2, 8-10]. Subsequently, an analysis aimed at assessing emissions from the aircraft's engine can be carried out. To do so, it is necessary to develop a working methodology.

The variable operating conditions of a multirole fighter aircraft and the variable operating conditions of its turbine engine cause a problem in assessing exhaust emissions in such aircraft operation. Therefore, this article makes an attempt to develop a method of estimating the exhaust emissions from multirole fighter aircrafts in their actual operating conditions. An important issue in assessing the exhaust gas emission of a turbine engine is the assessment of the engine exhaust flue gas generation in real flight conditions.

\section{Methodology}

The concept of the internal combustion engine operation is aimed at obtaining operating parameters that translate into propulsion. For turbine jet engines the flow of the exhaust stream is essential to generating thrust. According to the basic equation defining thrust, the mass and velocity of the exhaust gas flow is important. These indicators relate to operating parameters such as air intake and fuel consumption, which translate into the total mass of the exhaust gas generated by the engine (Fig. 3). Knowing the instantaneous value of the fuel consumption and measuring the chemical composition of the exhaust gases, to enable determination of the instantaneous value of the air-fuel ratio $\lambda$, the air mass fed to the engine in time can be estimated.

The sum of fuel consumption and air intake corresponds to the flow of exhaust gas generated:

$$
\dot{m}_{\text {air }}+\dot{m}_{f}=\dot{m}_{\text {exh }}
$$

where:

$\dot{m}_{\text {air }}$ - air mass flow,

$\dot{m}_{f}-$ fuel mass flow,

$\dot{m}_{\text {exh }}-$ exhaust gas mass flow.

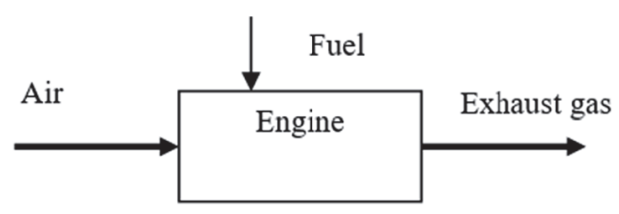

Fig. 3. Diagram of the input and output of a turbine jet engine.

Assuming that it is possible to measure two of these three values, the third value can be calculated. Therefore, a study was conducted with the aim of measuring the fuel consumption and the size of the stream of exhaust emitted and simultaneously measuring the concentrations of harmful exhaust compounds and airfuel ratio $\lambda$.

The assessment of exhaust gas emission in real operating conditions was performed on the basis of the F100-PW-229 engine performance record (Fig. 4) recorded during the F-16 multirole fighter flight (Fig. 5).

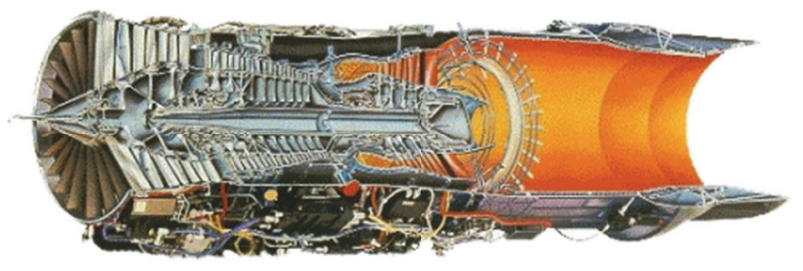

Fig. 4. F100-PW-229 engine cutaway drawing [1].

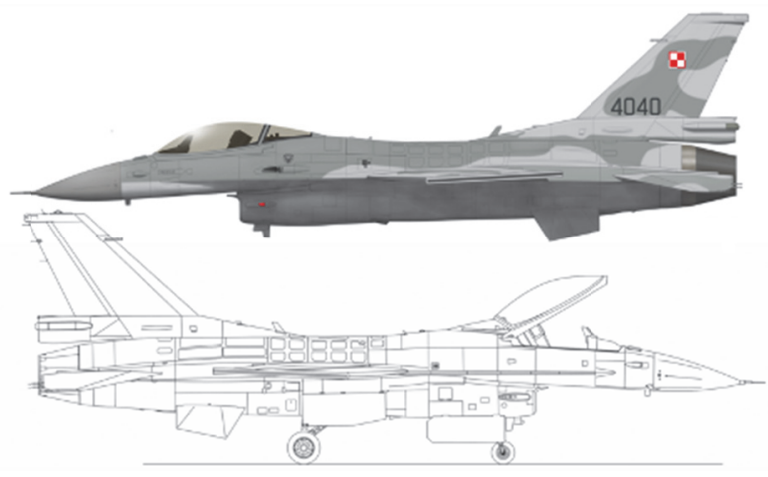

Fig. 5. F-16 multirole fighter aircraft.

The Pratt \& Whitney F100-PW-229 engine is a twoshaft unit with a hydraulically adjustable nozzle. It is equipped with a three-stage low-pressure compressor and a 10-stage high-pressure compressor. The combustion chamber is annular. Its maximum thrust values are $79.13 \mathrm{kN}$ - without the use of afterburner and $128.91 \mathrm{kN}$ with afterburners enabled.

The assessment of the exhaust gas during aircraft operation required an analysis of many parameters in terms of relating the engine performance with the characteristics of the generated exhaust gases. The procedure is illustrated in an example analysis.

\section{Result analysis}

Analyzed data were recorded by on-board flight recorders during over ten patrol and training flights. Figure 6 shows an example of changes in engine 
operation parameters recorded during one of such flights. Considering the relative thrust force values $\left(K / K_{n}\right)$ depending on a number of engine operation parameters and present in each operation phase, it is possible to present those values as a function of the relative value of engine speed $\left(n_{1}\right)$. By linking each operation phase to values recorded during the flight, the authors were able to determine operation areas defined by thrust force as a function of engine speed $\left(n_{1}\right)$.

Flight profiles can be described on the basis of the distribution of points corresponding to given phases. For the most part, points corresponding to the engine start-up and warming up phase are located in the area within $K / K_{\max }=40 \%$ and corresponding to the low-pressure stage speed $n_{1} / n_{1 \text { nom }}=70 \%$. A number of points from this particular phase are located outside the said area they denote the verification of correct operation of exhaust nozzle opening controller. The identified operation area also contains a number of points assigned to the taxiing phase and partially to the landing phase. The latter can be divided into two stages.

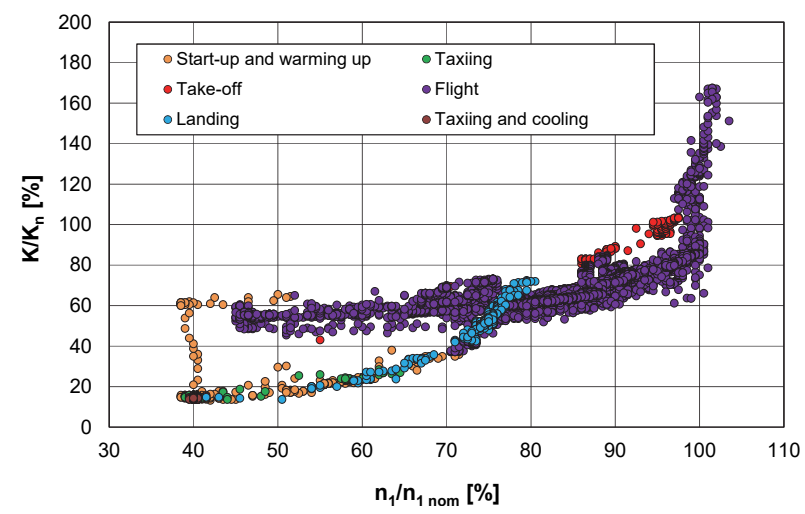

Fig. 6. Analyzed parameters in the engine operation range, recorded during the flight.

The first stage corresponds to the approach to land, whereby engine operation parameters stay in the range typical of actual flight $\left(K / K_{\max }=40-80 \%, n_{1} / n_{1 \text { nom }}=\right.$ $=70-80 \%)$. The other stage is landing, whereby engine parameters are lower $\left(K / K_{\max }=40 \%, n_{1} / n_{1 \text { nom }}=70 \%\right)$. A similar division can be proposed for the take-off phase. In the first stage, i.e. acceleration and take-off proper, one can identify an area corresponding to the range of $K / K_{\max }=100 \%$ and $n_{1} / n_{1 \text { nom }}=96 \%$. The other stage corresponds to the ascent after take-off $\left(K / K_{\max }=\right.$ $=80-90 \%$ and $n_{1} / n_{1 \text { nom }}=85-90 \%$ ). The example of relative thrust force and fan speed values during the take-off relates to a plane taking off with the afterburner off and with a small load. If a plane takes off fully loaded, the afterburner is usually off. The afterburner increases the engine's propulsion force by approximately $70 \%$. The extra force comes mostly from the mass of fuel additionally combusted in the afterburner chamber, located downstream of the engine's turbine assembly. The energy generated from fuel delivered to the afterburner chamber increases the energy of exhaust gas ejected from the exhaust nozzle, and thus the overall thrust force. Simultaneously it needs to be emphasized that afterburner status does not affect engine speed parameters $\left(n_{1}\right.$ and $\left.n_{2}\right)$. The flow of air through the engine corresponds to values occurring at maximum thrust obtained with the afterburner off. The range of engine operation with the afterburner on covers relative thrust force points in excess of $K / K_{\max }=105 \%$. The largest operation area covers points from the flight phase $\left(K / K_{\max }=40-170 \%\right.$ and $n_{1} / n_{1 \text { nom }}=45-105 \%$ of the low pressure stage speed). It is evident that this phase contains diverse values of the relative thrust force as a function of engine speed $\left(n_{1}\right)$. The above analysis shows that operation of a low dual flow jet engine fitted in a multi-purpose aircraft stays in the following ranges: $n_{1} / n_{1 \text { nom }}=38-105 \%$ and $K / K_{\max }=40-170 \%$.

The above division of relative thrust force values $\left(K / K_{\max }\right)$ as a function of relative engine speed $\left(n_{1} / n_{1}\right.$ nom $)$ made it possible to identify the ranges of operation phases. Relative thrust force values below $K / K_{\max }=40 \%$ and relative engine speed up to $n_{1} / n_{1 \text { nom }}=70 \%$ usually correspond to engine start-up, warming up, taxiing and cooling. Most of the range of $K / K_{\max }=40-100 \%$ and $n_{1} / n_{1 \text { nom }}=45-105 \%$ corresponds to take-off and flight, as well as to the approach to land stage of the landing phase. Points in the operation range of $K / K_{\max }=100$ $170 \%$ and $n_{1} / n_{1 \text { nom }}=95-105 \%$ correspond to afterburner on situations: these points represent the take-off phase and the maximum engine operation parameters during special maneuvers.

The example distribution of the engine operating parameters, expressed as relative power lever setting values, as a function of the relative shaft speed values $n_{l}$ indicate the potential for different engine load values for the individual shaft speeds. Consequently, additional parameters must be used to determine the operating status of the engine.

Among the recorded flight parameters and engine performance parameters, the parameters closely related to the engine load are the speed of the exhaust gas generator shaft $n_{2}$, the exhaust gas temperature before the turbine $T_{3}$, and the fuel consumption $G_{e}$. By comparing these values with each other and the value of exhaust gas temperature $T_{3}$, you the load factor of engine $W_{p}$ can be established (2).

$$
W_{p}=\frac{n_{2}}{T_{3}} \quad\left[\frac{\mathrm{rpm}}{\mathrm{K}}\right]
$$

where:

$n_{2}-n_{1}$ shaft rotational speed,

$T_{3}$ - exhaust gas temperature before the turbine.

By substituting the example values for the minimum load $n_{2}=10,064 \mathrm{rpm}, T_{3}=666 \mathrm{~K}$ and maximum load $n_{2}=13,590 \mathrm{rpm}, T_{3}=1276 \mathrm{~K}$ the following equations were obtained:

$$
\begin{array}{ll}
W_{\mathrm{p} \text { min }}=\frac{10064}{666}=15.11 & {\left[\frac{\mathrm{rpm}}{\mathrm{K}}\right]} \\
W_{\mathrm{p} \text { max }}=\frac{13590}{1276}=10.65 & {\left[\frac{\mathrm{rpm}}{\mathrm{K}}\right]}
\end{array}
$$

In this way a certain kind of inverse value is obtained, namely the minimum load factor is characterized by a large value and the maximum load factor by small. Additional information about the engine 
load can be obtained taking into account the excess air ratio [4]. The value of this parameter was determined on the basis of stationary assessment of the exhaust gas composition carried out for the analyzed engine performed at an engine dynamometer. These studies have shown the dependence of the excess air ratio value on the load [4]. Its values are respectively $\lambda_{p \min }=8.5$ at the smallest engine load and $\lambda_{p \max }=6.5$ at the highest load. Values of the following parameters: engine load $W_{p}$ and air excess ratio $\lambda$, are characterized by similar relations relative to the engine load $(5,6)$.

$$
\begin{aligned}
& \frac{W_{\mathrm{p} \min }}{W_{\mathrm{p} \max }}=\frac{15.11}{10.65}=1.41 \\
& \frac{\lambda_{\mathrm{p} \min }}{\lambda_{\mathrm{p} \max }}=\frac{8.5}{6.5}=1.31
\end{aligned}
$$

Consequently, the excess air excess ratio $\lambda$ must be linked to the determined load factor of the engine $W_{p}$. Hence the relation $(7,8)$ was proposed as:

$$
\begin{aligned}
& Z_{w-\lambda}=\frac{W_{\mathrm{p} \min }}{\lambda_{\min }}=\frac{15.11}{8.5}=1.70 \quad\left[\frac{\mathrm{K}}{\mathrm{rpm}}\right] \\
& Z_{w-\lambda}=\frac{W_{\mathrm{p} \max }}{\lambda_{\max }}=\frac{10.65}{6.5}=1.63\left[\frac{\mathrm{K}}{\mathrm{rpm}}\right]
\end{aligned}
$$

Taking into account the similarity in the obtained relationships, the mean value can be used for further calculations $Z_{\mathrm{w}-\lambda}=1.67\left[\frac{\mathrm{K}}{\mathrm{rpm}}\right]$.

As a result, the following equation (9) can be established:

$$
\lambda=\frac{W_{p}}{Z_{w-\lambda}} \quad\left[\frac{\frac{\mathrm{rpm}}{\mathrm{K}}}{\frac{\mathrm{K}}{\mathrm{rpm}}}\right]=[-]
$$

This equation is complementary to the equation for the determination of the air mass flow using fuel consumption (10):

$$
\dot{m}_{\mathrm{p}}=G_{e} \cdot \lambda \cdot 14.5 \quad\left[\frac{\mathrm{kg}}{\mathrm{h}}\right]
$$

Where the above equation takes the form (11):

$$
\dot{m}_{\mathrm{p}}=G_{e} \cdot \frac{w_{p}}{Z_{w-\lambda}} \cdot 14.5 \quad\left[\frac{\mathrm{kg}}{\mathrm{h}}\right]
$$

The obtained relation in equation (1) allows to determine the value of the emitted flue gas based on the operating parameters recorded by the onboard flight recorder using the equation (12).

$$
G_{e} \cdot \frac{W_{p}}{Z_{w-\lambda}} \cdot 14.5+G_{e}=\dot{m}_{e x h} \quad\left[\frac{\mathrm{kg}}{\mathrm{h}}\right]
$$

Using the listed equations, an analysis of the exhaust gas flow estimation of a multirole fighter aircraft turbine engine during a default flight was performed.

According to the presented set of equations, the values of the following operating parameters were used in the calculation: temperature before turbine $T_{3}$, shaft speed of flue gas generator $n_{2}$, and fuel consumption $G_{e}$. The results are graphically presented in Figure 7. Parameter changes described as time functions show a notable similarity between the $T_{3}$ temperature characteristic and the shaft rotational speed of the flue gas generator $n_{2}$. Changes in these parameters result from changes in the fuel consumption $G_{e}$, as they are a consequence of fuel combustion in the engine combustion chamber. Depending on the combustion process resulting from the load of the engine, the airflow change characteristics $G_{p}$ is obtained. From the described relationship, it can be identified as the main factor determining the value of the exhaust gas stream flowing from the engine $G_{\text {exh }}$.
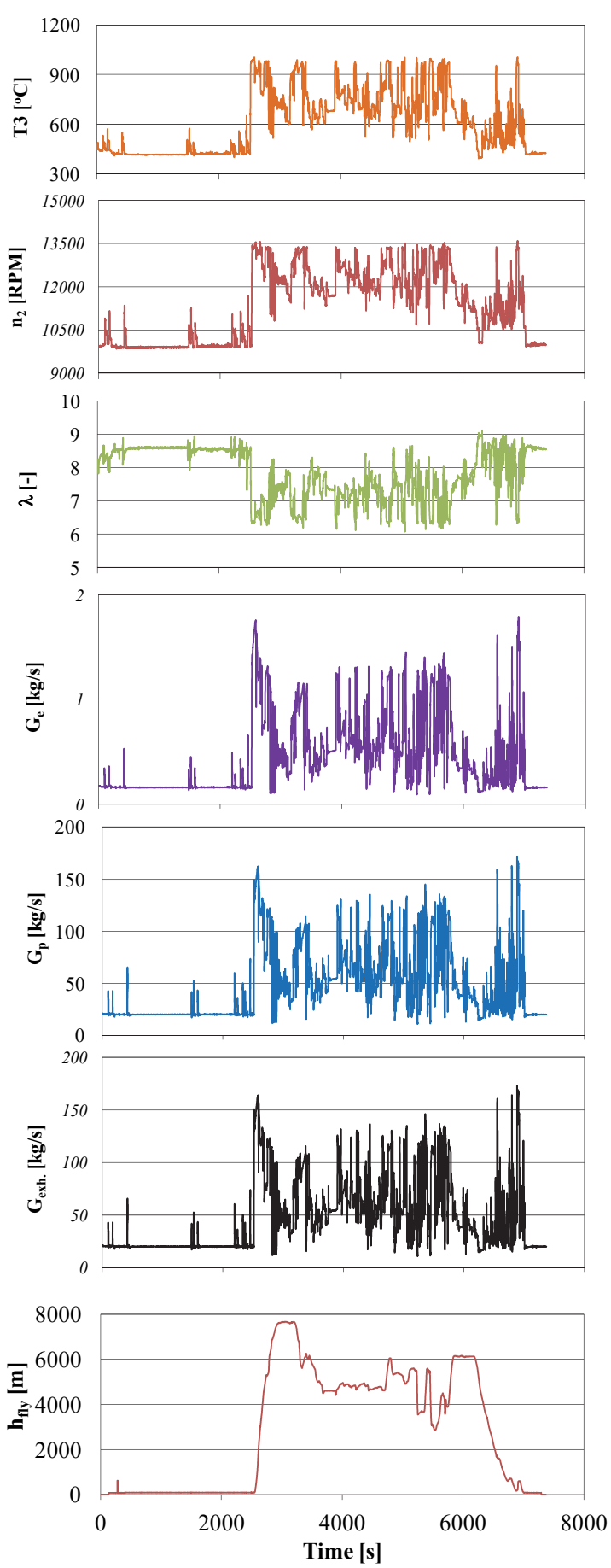

Fig. 7. Variable values of operating parameters as a function of time; Recorded parameters: $T_{3}, n_{2}, G_{e}, h_{f l y}$; calculated parameters: $\lambda, G_{p}, G_{e x h}$. 
The changes of these parameters along with the $h_{f l y}$ flight characteristics presented in the bottom graph, highlight the flight characteristics that are specific to multirole fighter aircraft.

Taking into account the 1 second time resolution of the recorded parameters, the individual values can be summed up during the entire recorded flight performed by the aircraft. As a result, it was reported that during a flight lasting 7368 seconds, that is 2 hours, 2 minutes and 48 seconds, the F100-PW-229 engine powered aircraft consumed $3297 \mathrm{~kg}$ of fuel, used $348,003 \mathrm{~kg}$ of air and generated $351,301 \mathrm{~kg}$ of exhaust.

\section{Conclusions}

The analysis of the interdependence of the recorded operating parameters was carried out to evaluate the possibility of determining the instantaneous value of the flue gas generated by the turbine engine when operating in high load parameters. The analysis showed that there are relationships between the parameters recorded by the flight recorder during the aircraft flight. The analysis has also shown that information derived from the engine emission characteristics is required in the form of an excess air ratio $\lambda$ value, which is necessary to establish the relationship of the combustion process in the engine to its load. The emission characteristics of the engine in the form of harmful exhaust gas emissions concentration values will be used in the next steps to determine the instantaneous emission values of the pollutants during the aircraft flight.

The study presented in this article was performed within the statutory research (contract No. 05/52/DSPB/0244).

\section{References}

1. P. Wygonik, Journal of KONES (2012)

2. J. Merkisz, J. Markowski, J. Pielecha, Selected Issues in Exhaust Emissions from Aviation Engines (Nova Science Publishers, 2014)

3. V. Ramanathan, Y. Feng, Atmospheric Environment 43 (2009)

4. S. Capoccitti, A. Khare, U. Mildenberger, Journal of Technology Management \& Innovation 5, 2 (2010)

5. A.K. Chaturvedi, Journal of Analytical Toxicology 34 (2010)

6. M. Masiol, R.M. Harrison, Atmospheric Environment 95 (2014)

7. ICAO Annex 16, Vol. 2 - Environmental Protection - Aircraft Engine Emissions. ICAO (2008)

8. J. Merkisz, J. Pielecha, S. Radzimirski, Springer Tracts on Transportation and Traffic 4, 1-170 (2014), DOI: 10.1007/978-3-319-02705-0

9. J. Merkisz, J. Pielecha, S. Radzimirski, Springer Tracts on Transportation and Traffic 4, 67-90 (2014), DOI: 10.1007/978-3-319-02705-0_4
10. J. Merkisz, J. Markowski, J. Pielecha, D. Karpinski, M. Galant, 18 ETH-Conference on Combustion Generated Nanoparticles (Zurich, 2014) 